\title{
Studies in meotropical polypores 7. Wrightoporia (Hericiaceae, Basidiomycetes) in tropical America
}

\author{
LEIFRYVARDEN
}

RYVARDEN, L. 2000: Studies in neotropical polypores 7. Wrightoporia (Hericiaceae,
Basidiomycetes) in tropical America. - Karstenia 40: 153-158. Helsinki. ISSN 04533402 .

Wrightoporia neotropica Ryvarden is described as new and a key and descriptions are provided for all known species of Wrightoporia in tropical America.

Key words: polypores, Tropical America, Wrightoporia

Leif Ryvarden, Department of Botany, Biological Institute, University of Oslo, P.O. Box 1045, Blindern, N-0316 Oslo,Norway.E-mail: leif.ryvarden@bio.uio.no

\section{Introduction}

Dai (1995) has given an excellent survey of how the genus Wrightoporia Pouzar has been expanded since it was described in 1966 and to which the reader is referred for details.

The genus belongs in the Hericiaceae due to its amyloid spores, usually ornamented, combined with a dimitic hyphal system where the skeletal hyphae have a dextrinoid reaction in many species. Gloeocystidia and/or gloeopleurous hyphae are present in many species as well.

Amylonotus Ryvarden was described on basis of $A$. africanus Ryvarden, a deep brown species reminding strongly about an Inonotus species on sight. David \& Rajchenberg (1987) rejected this genus and put it in synonymy with Wrightoporia. Future DNA investigations will show whether we are confronted with a true phylogenetic relationship or a case of convergence.

Amylosporus Ryvarden is based on Tyromyces graminicola Murr, a pantropical, white almost stipitate species growing on the ground, presumably as a gras parasite. David and Ra- jchenberg (1987) expanded the genus in adding several other species based on microscopical considerations. However, I feel that the stipitate habitat and its ecology make Amylosporus a distinct genus, separated from the resupinate woodinhabiting basidiocarp of Poria lenta Overh. \& Lowe, the type species of Wrightoporia. Thus it is excluded in this treatment.

\section{Taxonomy}

Wrightoporia Pouz., Česká Mykol. 20:173, 1966. Basidiocarps resupinate to pileate, annual to perennial; pores small to medium, white to cream or gray; hyphal system dimitic; generative hyphae with clamps or simple septa, thick-walled to solid, dextrinoid to non-dextrinoid; basidiospores less than $6 \mu \mathrm{m}$ in largest dimension, globose to cylindrical, smooth to ornamented, weakly to strongly amyloid. On dead wood, both of gymnosperms and angiosperms. Cosmopolitan genus. Type species: Poria lenta Overh. \& Lowe. 


\section{Key to neotropical species:}

1. Basidiocarps perennial, resupinate to effused reflexed, woody hard, pore surface grey to pale brown W. tropicalis

1. Basidiocarp annual to biennial, resupinate to distinctly pileate, soft to fragile, pore surface pinkish to ochraceous or wood coloured

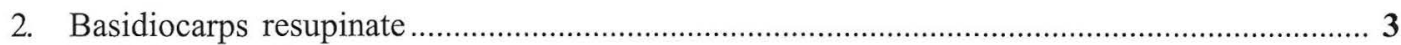

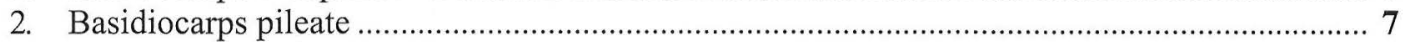

3. Pore surface pinkish to lilac .................................................................................. W. bracei

3. Pore surface whitish, ochraceous to pale straw coloured ................................................... 4

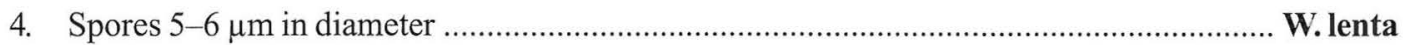

4. Spores $3.5-4.5 \mu \mathrm{m}$ in longest dimension ............................................................................. 5

5. Pores 1-3 per mm, irregular, basidiocarp soft, cottony easy to separate from the substrate ... W. avellanea

5. Pores tiny $6-8$ per $\mathrm{mm}$, basidiocarp hard to tough, adnate 6

6. Skeletal hyphae dextrinoid, generative hyphae with clamps

W. neotropica

6. Skeletal hyphae non-dextrinoid, generative hyphae with simple septa W. efibulata

7. Upper surface chestnut coloured W. brunneo-ochracea

7. Upper surface wood coloured or ochraceous ... 8

8. Pores 1-3 per mm, spores subcylindrical to oblong ellipsoid W. porilacerata

8. Pores 3-4 per mm, spores subglobose W. cremea

Wrightoporia avellanea (Bres.) Pouz., Ceská Mycol. 20:173, 1966. - Poria avellanea Bres. in v. Höhnel, K. Akad. Wiss. Math. Naturw. Klas. Denk. Schr. 83:14, 1907.

Basidiocarp annual, resupinate, becoming widely effused, up to $12 \mathrm{~cm}$ in diameter and $8 \mathrm{~mm}$ thick, easily separable from the substrate, margin white to pale fulvous, membranaceous to arachnoid, often with several lobes, consistency soft fibrous-tough when dry; pore surface cream to pale fulvous, often with darker brown patches, dull, pores round to more irregular on near vertical surfaces, 1.5-3 per mm, dissepiments thin to rather thick; tubes up to $8 \mathrm{~mm}$ long, concolorous or slightly paler than the pore surface; subiculum fibrous, up to $1 \mathrm{~mm}$ thick, concolorous and continuing without change into the dissepiments. Hyphal system dimitic; generative hyphae clamped, hyaline and thin-walled, $1.5-2.5 \mu \mathrm{m}$ in diameter; skeletal hyphae dominating in the fruit- body, thick-walled to solid, hyaline to pale yellow, sometimes weakly branched, 1.5-2(3) $\mu \mathrm{m}$ wide, thick-walled, strongly dextrinoid. Cystidia and other sterile hymenial elements absent. $B a$ sidia clavate, 4-sterigmate, 10-14 × 4-6 $\mu \mathrm{m}$. Basidiospores subglobose to broadly elliptical, hyaline, slightly asperulate, thin- to slightly thick-walled, 3.5-4.5 × 2.5-3.5(4) $\mu \mathrm{m}$, distinctly amyloid.

Substrata: Most common on deciduous wood, rarely on conifers.

Distribution: Widespread in the tropics, in the neotropics seen from Brazil, Jamaica, French Guiana, Venezuela.

Remarks: The species is recognized by the fairly large pores.

Wrightoporia bracei (Murr.) Lindblad \& Ryvarden, Mycotaxon 71:357, 1999. - Polyporus bracei Murr. Mycologia 13:91,1921. - Amylosporus wrightii Rajchenb., Mycotaxon 16:500, 1983. 
Basidiocarp annual to perennial, resupinate, widely effused, up to $8 \mathrm{~mm}$ thick, soft when fresh and of light consistency when dry, easily detached from the substrate, pore surface pale violet to pink or lilac, pores angular, 5-7 per $\mathrm{mm}$, in places irregular in dry basidiocarps, tubes and context concolorous with tubes in fresh condition becoming darker when dry, the context cottony and soft, up to $4 \mathrm{~mm}$ deep. Hyphal system dimitic, generative hyphae of two kinds, those of the context with simple or multiple clamps, up to $10 \mu \mathrm{m}$ wide, otherwise the generative hyphae have simple septa, 3-10 $\mu$ m wide, skeletal hyphae thick-walled, chestnut coloured to hyaline, in places branched and then simulating generative hyphae, 2.5-7 $\mu \mathrm{m}$ wide and with a variable dextrinoid reaction. Cystidia and other sterile hymenial elements absent. Basidia clavate with 4 sterigmata and a simple septum at the base, $12-14 \times 5-$ $7 \mu \mathrm{m}$. Basidiospores broadly ellipsoid to subglobose, slightly asperulate, thin- to slightly thickwalled, 3-3.5 $\times 2.5 \mu \mathrm{m}$, distinctly amyloid.

Substrata: Known only from unknown hardwoods.

Distribution: From the Bahamas to Northern Argentine.

Remarks: The species is recognized by the pinkish to lilac pore surface and a soft consistency. Microscopically the verticillate clamps on the contextual generative hyphae mixed with simple septate ones are diagnostic.

\section{Wrightoporia brunneo-ochracea David \& Rajchenb., Mycotaxon 22:319, 1985.}

Basidiocarp annual,effused reflexed, pileus up to $1 \mathrm{~cm}$ wide, upper surface cottony adpressed, chestnut coloured, pore surface cream to woodcoloured, pores irregular to angular, 3-4 per mm, some elongated to $2 \mathrm{~mm}$, tubes concolorous with pore surface, context, duplex, the lower part concolorous with the tubes, the upper part pale chestnut-coloured. Hyphal system dimitic to trimitic?; generative hyphae clamped, hyaline and slightly thick-walled $2.4 \mu \mathrm{m}$ in diameter with some strongly branched side branches that may be taken for binding hyphae; skeletal hyphae thick-walled to solid, 2-6 $\mu \mathrm{m}$ wide, without dextrinoid reaction. Cystidia and other sterile hymenial elements absent. Basidia not seen. Basidiospores ellipsoid, asperulate, thin- to slightly thick-walled, 3-3.5 × $2 \mu \mathrm{m}$, distinctly amyloid.
Substrata: Known only from an unknown hardwood tree.

Distribution: Known only from the type locality in Guadeloupe

Remarks: The species is recognized by chestnut coloured pileus and the duplex context besides the ellipsoid spores.

Wrightoporia cremea Ryvarden, Mycotaxon 28:540, 1987.

Basidiocarp annual, pileate, broadly attached, up to $3 \mathrm{~cm}$ wide and long, upper surface cream to pale ochraceous, velutinate to glabrous, azonate consistency corky to soft fibrous-tough when dry; pore surface cream to wood-coloured, pores round to angular, 3-4 per $\mathrm{mm}$, dissepiments thin to rather thick; tubes concolorous with pore surface, in the type with the distinct layers (biannual?), context, concolorous and up to $3 \mathrm{~mm}$ thick. Hyphal system dimitic; generative hyphae clamped, hyaline and thin-walled, $1.5-3 \mu \mathrm{m}$ in diameter; skeletal hyphae thick-walled to solid, 2-5 $\mu \mathrm{m}$ wide, strongly dextrinoid. Cystidia and other sterile hymenial elements absent. Basidia not seen. Basidiospores subglobose, slightly asperulate, thin- to slightly thick-walled, $3-4 . \mathrm{mm}$ in diameter or longest dimension, distinctly amyloid.

Substrat:. Known only from an unknown hardwood tree.

Distribution: Known only from the type locality in Brazil: Amazona, Roraima.

Remarks: The species is recognized by the fairly large pores and cream coloured pileus besides the lack of cystidia.

Wrightoporia efibulata I.Lindblad \& Ryvarden, Mycotaxon 71:355, 1999.

Basidiocarps annual, resupinate, up to $1 \mathrm{~mm}$ thick, easily separable from the substrate, consistency soft when fresh, brittle when dry. Margin white to buff, cottony, irregular, sterile. Pore surface white with a rose tint when fresh, white, buff to rosy buff when dry, pores round, entire, thin-walled, slightly irregular in size, $6-8$ per $\mathrm{mm}$; tube layer concolorous with pores, up to $0.5 \mathrm{~mm}$ long; subiculum thin, up to $0.5 \mathrm{~mm}$. Hyphal system dimitic, generative hyphae hyaline, thinwalled, with simple septa, $3-8 \mu \mathrm{m}$ wide. Skeletal hyphae thick-walled to solid, hyaline, negative in Melzer's reagent, sinuous, $4-8 \mu \mathrm{m}$ wide. Cystidia and other sterile hymenial elements absent. $\mathrm{Ba}$ sidia not seen. Basidiospores globose, hyaline, 
very finely asperulate, thin-walled, amyloid, 3$3.5 \mu \mathrm{m}$ in diam.

Substrate: On dead hardwoods.

Habitat: Collected in tropical moist forest.

Distribution: Known only from the type locality.

Remarks: The species is recognized by the small pores, the whitish adnate basidiocarp and above all by the consistently simple-septate generative hyphae and non-dextrinoid skeletal hyphae.

Wrightoporia lenta (Overh. \& Lowe) Pouz., Česká Mycol. 20:173, 1966. - Poria lenta Overh. \& Lowe, Mycologia 38:210, 1946.

Basidiocarp resupinate, effused, up to $3 \mathrm{~mm}$ thick, separable to slightly adnate, tough when dry; pore surface white to cream, margin white, pores round to angular, often slightly sinuous on oblique substrates, on average $2-3 \mathrm{~mm}$, thinwalled, tubes concolorous with pore surface, up to $2 \mathrm{~mm}$ deep; context thin and white. Hyphal system dimitic; generative hyphae with clamps, 1-3 $\mu \mathrm{m}$ wide; skeletal hyphae thick-walled to solid, 1.5-3 $\mu \mathrm{m}$ wide, strongly dextrinoid; gloeopleurous hyphae rare and scattered, irregular and often with blunt side-branches, slightly yellowish when mounted in $\mathrm{KOH}$, but negative in Melzer's reagent, diameter variable, mostly 3-6 $\mu \mathrm{m}$, but parts up to $15 \mu \mathrm{m}$ wide. Cystidia and other sterile hymenial elements absent. Basidia clavate, 4-sterigmate, 15-20 × 4-8 $\mu \mathrm{m}$. Basidiospores globose, finely asperulate, hyaline, 5-6 $\times 4.5-5.5 \mu \mathrm{m}$, amyloid.
Type of rot: ssociated with a brown rot.

Substrat: On deciduous wood and palms.

Distribution: Widespread in southern United States, Central and South America and Africa. Remarks. The species is recognized by its basidiospores being larger than those of the other species in the genus.

Wrightoporia neotropica Ryvarden sp. nov. Fig. 1

Fructificatio resupinata, pori albidi vel cremei, 6-8 per mm, tubi et contexti cremei, systema hyphale dimiticum, hyphae generatoriae hyalinae, efibulatae, hyphae skeletales hyalinae, dextrinoideae, basidiosporae ellipsoideae, amyloideae, verrucosae, 3-3.5 (4) $\times 2.5-2.8 \mu$ m diametro.

Holotype: Venezuela. Estado Bolivar, Canaima National Park, Gran Sabana, Carretera ParupaKavanayen, 1300 m, on dead log of unknown hardwood, 20.XI.1994 Ryvarden 35135 (O, isotype VENN).

Etymology: neotropica - refers to the distribution.

Additional specimens examined: Dominican Republic. La Vega province, Casabito, Arroyaza, on dead hardwood, 29.V.1997 Ryvarden 40228 (O). Jamaica. Trewlany parish, Crowlands, on dead hardwood, 10.VI.1999 Ryvarden 41620 (O, IJ).

Basidiocarps annual, resupinate, up to $2 \mathrm{~mm}$ thick, adnate, tough, margin white to buff and rounded, pore surface white to cream or pale straw-coloured with age, pores round, entire, 68 per $\mathrm{mm}$; tube layer concolorous with pores, up

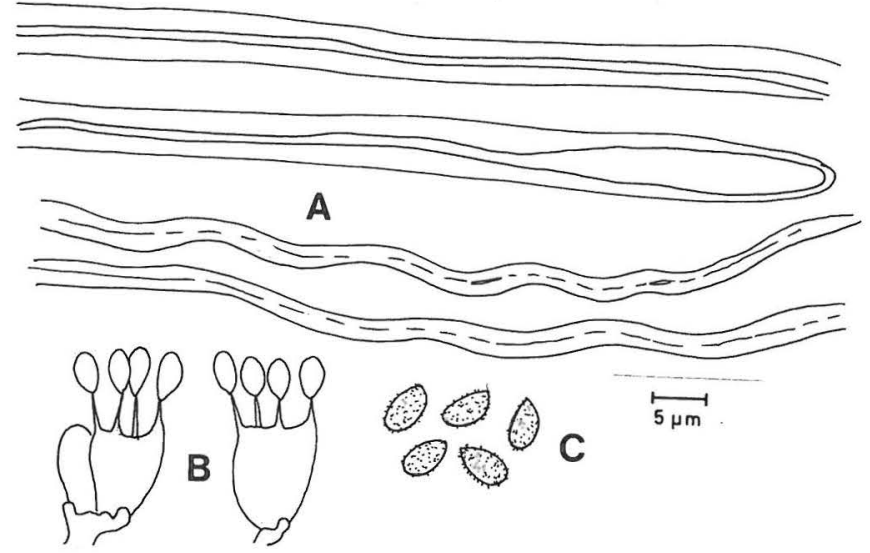

Fig. 1. Wrightoporia neotropica.- a. skeletal hyphae of two types, b. basidia, c. basidiospores. From the holotype. 
to $0.5 \mathrm{~mm}$ long; subiculum thin, up to $0.5 \mathrm{~mm}$. Hyphal system dimitic, generative hyphae hyaline, thin-walled, with clamps, 3-4 $\mu \mathrm{m}$ wide, skeletal hyphae thick-walled to solid, hyaline, dextrinoid in Melzer's reagent, especially in the dissepiments, partly straight and running parallel to the tubes giving the tubes a fibrous consistency, 4-6 $\mu \mathrm{m}$ wide, partly sinuous, and narrower, 2-3 $\mu \mathrm{m}$ wide. Cystidia and other sterile hymenial elements absent. Basidia barrel shaped, 8-10 × 6-8 $\mu \mathrm{m}$ with 4 sterigmata. Basidiospores ellipsoid, hyaline, very finely asperulate, thin-walled, amyloid, 3-3.5(4) × 2.5-2.8 $\mu \mathrm{m}$.

Type of rot: White rot.

Substrate: On dead hardwoods.

Distribution: Known from Jamaica, Dominican Republic and Venezuela, but will probably be shown to have a wider distribution when more collecting has been undertaken.

Remarks: The species is recognized by the tiny pores, the whitish, cream to pale straw coloured adnate basidiocarp and the dextrinoid skeletal hyphae. W. efibulata Lindblad \& Ryvarden has a similar basidiocarp, but easily separated by simple septate generative hyphae and nondextrinoid skeletal hyphae.

W. africana Johansen \& Ryvarden, so far known only from Africa, also has a resupinate basidiocarp, but has a soft to fibrous consistency and easily separated from the substrate with more irregular pores 4-6 per $\mathrm{mm}$ and narrower skeletal hyphae (1.5-4 $\mu \mathrm{m}$ wide in the tubes).

Wrightoporia porilacerata Leite, Gerber \& Ryvarden, Mycotaxon 67:252, 1998.

Basidiocarp annual, pileate, broadly attached, up to 13,5 long, $8.7 \mathrm{~cm}$ wide and $2 \mathrm{~cm}$ thick at the base, soft and fleshy when fresh, lightly of weight and fragile when dry, upper surface cream to pale ochraceous, glabrous, azonate; pore surface cream to wood-coloured, pores round to angular, 1-3 per mm, dissepiments thin and partly dentate; tubes concolorous with pore surface, in the holotype up to $1 \mathrm{~cm}$ deep, lighter than the tubes, cream to almost white, soft and cottony up to $3 \mathrm{~mm}$ thick. Hyphal system monomitic, generative hyphae with scattered clamps, hyaline and thin-to very thickwalled, 3-8 $\mu \mathrm{m}$ wide, very sparingly branched and segments of up to $400 \mu \mathrm{m}$ seen without a clamp, non-dextrinoid. The long segments without clamps may be interpreted as intercalary skeletal hyphae but since there are even transitions from the most delicately thin-walled hyphae to wide and almost solid ones, we interpret the thick-walled hyphae as so called sklerified generative hyphae. Cystidia and other sterile hymenial elements not seen. Basidia clavate, 8 $12 \times 4-5 \mu \mathrm{m}$ with 4 sterigmata and a basal clamp. Basidiospores subcylindrical to broadly ellip-

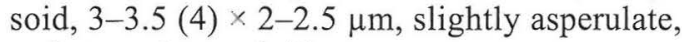
and strongly amyloid.

Substrata. Known only from an unknown hardwood tree.

Distribution: Known only from the type locality.

Remarks: The species is recognized by the large, fleshy ochraceous basidiocarps, fairly large pores, its monomitic hyphal system with strongly variable width and wall thickness besides the subcylindrical amyloid spores. W. cremea Ryvarden is separated by almost globose spores and dextrinoid skeletal hyphae.

Wrightoporia tropicalis (Cooke) Ryvarden, Prelim. polypore flora East Afr.: 619, 1980. - Fomes tropicalis Cooke, Grevillea 15: 22.1886.

Basidiocarp perennial, resupinate to effused reflexed, becoming widely effused, up to $15 \mathrm{~cm}$ in diameter and $2.5 \mathrm{~cm}$ thick, consistency woody, hard and dense when dry, pileus fragmentary or absent, appearing as a black upper portion of the pore surface especially on vertical substrata, glabrous, dull or slightly shining, smooth or weakly sulcate, the pilear surface is darker brown towards the pore surface, but there is no distinct margin, only a thin white line towards the sterile margin round the pore surface, pore surface pale grey or brown with a whitish tint, pores circular to slightly elongated in radial direction, $6-7$ per $\mathrm{mm}$, dissepiments thin and entire, tubes distinctly stratified, totally up to $2.5 \mathrm{~cm}$ long, each stratum up to $1.5 \mathrm{~mm}$ long, colour grey to brownish near the pore surface, but in thick specimens more fulvous, rusty red to bay in the older parts, context fragmentary or lacking, light rusty brown. Hyphal system trimitic, generative hyphae with simple septa, hyaline and thin-walled, $1.2-3 \mu \mathrm{m}$ wide, soon collapsing and then very difficult to septa, skeletal hyphae dominant, thick-walled to solid, yellow to pale brown, weakly to heavily dextrinoid in Melzer's reagent, 3-4 $\mu \mathrm{m}$ in diameter, sometimes a few skeletal hyphae become strongly swollen at the apex, simulating 
clavate cystidia, with a diameter up to $10 \mu \mathrm{m}$. they occur infrequently and have only been seen deeply embedded in the trama. Cystidia present as apical heavily encrusted ends of skeletal hyphae, crystal masses up to $20 \mu \mathrm{m}$ in diameter and obscuring the apical end of the skeletal hyphae. Gloeocystidia present, thin-walled to slightly thick-walled with granular to oily contents appearing refractive in phase contrast, $5-17 \mu \mathrm{m}$ in diameter, up to $150 \mu \mathrm{m}$ long, mostly embedded in the trama but also curving into the hymenium but not projecting beyond it. In dried specimens they are partly collapsed and difficult to tease apart. Basidiospores subglobose to broadly ellipsoid, hyaline, smooth to slightly verrucose (seen under SEM), thin-walled, 3-4 × 2-3 $\mu \mathrm{m}$, weakly to strongly amyloid.
Substrata: On deciduous wood.

Distribution: Neotropical species from Puerto Rico and Guadeloupe to Brazil.

Remarks: The species is separated from the other ones in the genus by its thick, woody hard basidiocarps, the greyish to pale brownish pore surface, the gloeocystidia and the heavily encrusted skeletal cystidia. Macroscopically it reminds one of Rigidoporus vinctus, but this species has simple septate generative hyphae and non-amyloid spores.

\section{References}

Dai, Y. C 1995: A new species of Wrightoporia (Basidiomycetes) from China. - Karstenia 35: 84-89.

David, A. \& Rajchenberg, M. 1987: A reevaluation of Wrightoporia and Amylonotus (Aphyllophorales, Polyporaceae). - Canadian J. Bot. 85: 202-208. 